\title{
Yoğun Bakım Ünitelerinde Çalışan Hemşirelerin Maruz Kaldıkları Fiziksel Zorlanmaların Analizi
}

\section{Analysis of Physical Forces Exposed by Nurses Working in Intensive Care Units}

\author{
(Araştırma)
}

\author{
Ebru ARSLAN ÖZDEMIR* Özlem ÖRSAL**
}

öz

\begin{abstract}
Amaç: Yoğun Bakım ünitelerinde görev yapan hemşireler vardiya boyunca, kendi kilolarından çok daha fazla ağırlıkta olan hastaları, kaldırma, itme, çevirme gibi fiziksel zorlanma gerektiren faaliyetleri yerine getirmektedir. Bu çalışmanın amacı; ergonomik risk analizine göre yoğun bakım ünitelerinde çalışan hemşirelerde gözlenen tekrarlı hareketlerden hastaya pozisyon verme faaliyetinin kas-iskelet sistemi rahatsızlıkları ile ilişkisini değerlendirmektir.

Gereç ve Yöntem: Çalışma Şubat-Nisan 2017 tarihleri arasında araştırmacılar tarafından hazırlanan tanımlayıcı bilgiler formu ve REBA çalışan değerlendirme formu kullanılarak anket ve gözlem yoluyla bir devlet hastanesinin beş adet yoğun bakım ünitesinde çalışan 98 hemşire ile tamamlanmıştır.

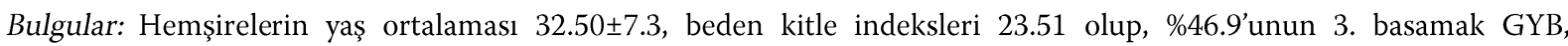
\%29.6'sının 2. basamak GYB, \%9.2'sinin Koroner YB, \%6.1'inin Göğüs YB ve \%8.2'sinin Nöroloji YB'da görev yaptı̆̆ bulunmuştur. Çalışmamızda hemşirelerin tekrarlı hareketlerde bulundukları pozisyon verme işleminde vücut postürü değerlendirmesi sonucunda REBA'dan aldıkları ortalama puan $8.71 \pm 1.74$ ( min. 5.00 - maks. 13.00) olup, hemşirelerin \%63.3’ünün yüksek derecede risk altında olduğu bulunmuştur. Boyun bölgesinde, omuz bölgesinde, sirt bölgesinde ve ayakayak bileğinde ağrısı olan hemşirelerin REBA puanları daha yüksektir ( $\mathrm{p}<.05)$.

Sonuç: Yoğun bakımda çalışan hemşirelerin çoğunda kas iskelet problemi bulunmaktadır. Yoğun bakımlarda hastaya pozisyon verme işleminde hemşirelerin yükünü azaltan yatakların / yardımcı cihazların kullanılması yararlı olacaktır.

Anahtar Kelimeler: Hemşirelik, kas-iskelet sistemi, postür, yoğun bakım üniteleri
\end{abstract}

\section{ABSTRACT}

Aim: During the shift, nurses working in intensive care units perform activities that require physical strain such as lifting, pushing and turning patients who weigh much more than their own weight. The aim of this study is to evaluate the relationship between the repetitive movements observed in nurses working in intensive care units and musculoskeletal disorders according to ergonomic risk analysis.

Material and Methods: This study was conducted with 98 nurses working in five intensive care units of a state hospital between February-April 2017 by using a questionnaire developed by the researchers and REBA employee evaluation form through observations.

*Hemşire, Atatürk Devlet Hastanesi, Zonguldak, Türkiye. E-mail: ebruaarslan@gmail.com, Tel: 0531420 96 53, ORCID: https://orcid.org/0000-0003-4540-7528 **Doç. Dr., Eskişehir Osmangazi Üniversitesi Sağlık Bilimleri Fakültesi Hemşirelik Bölümü, Eskişehir, Türkiye. E-mail: ozlorsal@gmail.com, Tel: 0222 239 37 50/26480, ORCID: https://orcid.org/0000-0002-4012-7036

Geliş Tarihi: 11 Kasım 2018, Kabul Tarihi: 21 Ağustos 2019

***Bu çalışma 28-30 Eylül 2018 tarihinde Erzurum' Türkiye'de gerçekleştirilen 24. Ulusal Ergonomi Kongresinde sözel bildiri olarak sunulmuştur. Atıf/Citation: Arslan Özdemir E, Örsal Ö. Yoğun Bakım Ünitelerinde Çalışan Hemşirelerin Maruz Kaldıkları Fiziksel Zorlanmaların Analizi. Hacettepe Üniversitesi Hemşirelik Fakültesi Dergisi 2019; 6(3): 158-169. 
Results: The mean age of the nurses was $32.50 \pm 7.3$ and the mean body mass index was 23.51. It was found that $46.9 \%$ of the nurses worked in $3^{\text {rd }}$ stage ICU, 29.6\%, $2^{\text {nd }}$ stage ICU, 9.2\% in Coronary ICU, 6.1\% in Chest ICU and 8.2\% in Neurology ICU. was also found. In our study, the mean score obtained from REBA was $8.71 \pm 1.74$ (min. 5.00 - max. 13.00) as a result of body posture evaluation in the repetitive movements of the nurses and $63.3 \%$ of the nurses were found to be at high risk. The REBA scores of the nurses with neck, shoulder, back and ankle pain were higher $(\mathrm{p}<.05)$.

Conclusion: Most of the nurses working at intensive care unit have musculoskeletal problems. It will be beneficial to use beds / assist devices which reduce the burden of nurses in patient positioning in intensive care units.

Key Words: Intensive care units, musculoskeletal system, nursing, posture

\section{GíRiş}

Çalışma zamanını geçirdiğimiz iş yerleri ile sağlık durumu arasında karşılıklı bir etkileşim mevcuttur. İş yerlerinde, çalışılan şartlardan ve yürütülen işlerden kaynaklanan, sağllğı olumsuz yönde etkileyen bazı riskler bulunmaktadır ${ }^{1-3}$. Bu risklerin sonucu olarak ortaya çıkabilen kazalar; malzeme kayıplarına ve iş ekipmanı hasarlarına neden olduğu gibi, çalışanların yaralanmalarına, hastalanmalarına ve ölümlerine de neden olabilmektedir". Dünya Sağlık Örgütü işle ilgili hastalıkları; "Sadece bilinen meslek hastalıkları değil, gelişmesinde ve meydana çıkmasında; çalışma ortamı ve koşullarının önemli olduğu hastalıklar” olarak tanımlamaktadır".

National Institute for Occupational Safety and Health (NIOSH / Ulusal İş Sağlığı ve Güvenliği Enstitüsü) tarafından hastanelerdeki ergonomik riskler; uygun olmayan postürde çalışma ve oturma, uzun süreli ayakta kalma, ağır ekipman ve hastaların taşınması ve transferleri esnasında oluşabilecek riskler olarak tanımlanmıştır. Yoğun bakım ünitelerinde görev yapan hemşireler vardiya boyunca, kendi kilolarından çok daha fazla ağırlıkta olan hastaları, kaldırma, itme, çevirme gibi fiziksel zorlanma gerektiren faaliyetleri yerine getirmektedir ${ }^{7,8}$.

Yapılan iş ile çalışan arasında uyumu sağlayan ergonomi basitçe; işçiye uyacak araçları, ekipmanı, çalışma ortamını ve görevleri işçiye uygun olarak tasarlayarak, daha akıllıca çalışmanın bir yoludur. Bu uyum sağlandığında çalışan üzerindeki stres azalmakta ve işler daha hızlı, daha kolay, daha güvenilir, daha verimli gerçekleşmektedir. Bu sayede çalışanın sağlığının ve iyiliğinin sürdürülebilirliği de sağlanmış olur . Çalışma ortamında ergonomik risk etmenlerinin uygun risk analizi yöntemleriyle saptanarak gerekli önlemlerin alınabilmesi ve bu risklere yönelik düzenlemelerin yapılması çalışanların sağlıklarının korunması ve geri kazanılması açısından önemlidir ${ }^{3,10}$. Çalışma ortamı kaynaklı maruziyetin en aza indirilmesiyle rahatsızlıkların da aza indirilebileceği düşünülmektedir. Fujishiro ve arkadaşlarının 1999-2003 yılları arasında Ohio'da 86 sağlık kuruluşunda yaptıkları çalışmada; hasta kaldırma ve taşıma için tasarlanan ergonomik araçların kullanımının işle ilgili kas iskelet sistemi bozukluğu semptomlarında azalma sağladığı aktarılmaktadır ${ }^{11}$. Hemşireler ayakta durma, ağırlık kaldırma, hatalı postürlerde uzun süre çalışma ve stres altında çalışma gibi etkenler nedeniyle diğer meslek dalları arasında işe bağlı kas ve iskelet hastalıklarına sahip olma sırasında en başlarda yer almaktadır²,12. Alp ve arkadaşlarının yoğun bakım hemşirelerinin de olduğu çeşitli meslek gruplarının değişik birimlerdeki çalışma postürünü değerlendirdikleri çalışmalarında; araştırmaya katılanların her bir vardiya boyunca ortalama ayakta durma süresinin 3.3 saat olduğu, ağırlık kaldırma sürelerinin ise ortalama 40 dakika aldığı aktarılmaktadır ${ }^{13}$. Pompei ve arkadaşlarının hemşireler üzerinde yaptıkları çalışmada; saptanan tüm kas-iskelet sistemi yaralanmalarının üçte birinin hasta taşıma faaliyetlerinden kaynaklandığı belirtilmektedir ${ }^{14}$. Pınar’ın çalışmasında hemşirelerde uygun olmayan çalışma duruşu ve ağır kaldırmanın bel ağrısının görülme riskini arttırdığı ve bel ağrısının hemşirelerde en sık görülen kas iskelet problemi olduğu aktarılmaktadır ${ }^{15}$. Literatür incelendiğinde yoğun bakım hemşirelerinin fiziksel zorlanmalara maruz kaldığı ve kas iskelet rahatsızlıkları yaşadıkları görülmektedir ${ }^{7,13,16,17,19}$. Yoğun bakım üniteleri, çalışanlara uygun bir şekilde tasarlanmadığında ve hasta bakımının fiziksel gereksinimi ile bakım veren hemşire arasında uyumsuzluk olduğunda kas-iskelet sistemi kaza ve yaralanmaları görülebilmektedir. Babayiğit; sağlık çalışanlarının yaşadığı mesleki ağrı ve hastalıkların oluşum sebeplerini; ergonomik faktörler, postür ve korunma prensiplerine dikkat edilmemesi olarak belirtmektedir ${ }^{8}$. Estonya'da yoğun bakım hemşirelerinin en çok yakınma yaşadıkları vücut bölgelerinin bel ve boyun olduğu, bu bölge ağrılarının mekanik sebeplerle geliştiği aktarılmaktadır ${ }^{16}$. Esin ve Sezgin yoğun bakım hemşirelerinin mesleki riskleri konusundaki derlemelerinde; yoğun bakım hemşirelerinin çalışma ortamında maruz kaldıkları tehlikeleri; uygunsuz çalışma koşulları, ergonomik, kimyasal, psikolojik etkenler ve kazalar olduğunu belirtmişlerdir ${ }^{17}$.

Çalışmanın katkısı üç alt başlıkta incelenecektir. Literatüre katkısı: hemşirelerin maruz kaldıkları fiziksel zorlanmaları içeren az sayıda çalışma olması sebebiyle benzer çalışmalara öncü olabileceği, yöneticilere katkısı: hemşirelerin fiziksel zorlanmaları dikkate alınarak gereken iyileştirmelerin yapılacağı, hemşirelere katkısı: işe bağlı kas iskelet sistemi rahatsızlıklarının hemşirelik mesleğindeki maruziyetinin saptanması açısından katkı sağlayacağı düşünülmektedir. Bu çalışmanın amacı; ergonomik risk analizine göre yoğun bakım ünitelerinde çalışan 
hemşirelerde gözlenen tekrarlı hareketlerden hastaya pozisyon verme faaliyetinin kas-iskelet sistemi rahatsızlıklarına ilişkisini değerlendirmektir.

\section{GEREÇ ve YÖNTEM}

\section{Araştırmanın Türü ve Amacı}

Çalışma 15 Şubat - 15 Nisan 2017 tarihleri arasında bir devlet hastanesinin 5 yoğun bakım ünitesinde çalışan hemşirelerde ergonomik risk analizine göre tekrarlı hareketlerin kas-iskelet sistemi rahatsızlıklarına etkisini belirlemek amacıyla yapılan tanımlayıcı ve kesitsel tipte bir araştırmadır.

\section{Araştırmanın Evren ve Örneklemi}

Çalışmanın evreni bir devlet hastanesinin 3. basamak genel yoğun bakım, 2. basamak genel yoğun bakım, koroner yoğun bakım, göğüs yoğun bakım ve nöroloji yoğun bakım olmak üzere beș yoğun bakım ünitesinde çalışan 101 hemşireden oluşmaktadır. 3. Basamak genel yoğun bakım ünitesinde bakım gören hastaların çoğu yatağa bağımlı ve mekanik solunum cihazı ihtiyacı olan hastalardan oluşmakta olup günlük yaşam aktivitelerinin neredeyse tamamında hemşirelere bağımlıdırlar. Bu bağımlılık 2. basamak genel yoğun bakım, nöroloji yoğun bakım, göğüs yoğun bakım ve koroner yoğun bakım ünitesine doğru giderek azalmaktadır. Koroner yoğun bakım ünitesindeki hastalar; bilinci açık, günlük yaşam aktivitelerinin çoğunu kendi karşılayabilen, mobilize ve monitöre bağlı hastalardan oluşmaktadır. Çalışmada örneklem seçimi yapılmamış olup, evrenin tamamına ulaşılması amaçlanmıştır. Çalışma evreninde bulunan 3 hemşire çalışma yoğunluğu sebebiyle araştırmaya zaman ayıramayacağını belirterek araştırmaya katılmayı kabul etmemiş, çalışma araştırmaya katılmaya gönüllü olan 98 hemşire (katılım oranı: \% 97.02) üzerinde yürütülmüştür.

Tablo 1. Araştırmanın evreni

\begin{tabular}{lll}
\hline $\begin{array}{l}\text { Yoğun Bakım } \\
\text { Üniteleri }\end{array}$ & Evren & Ulaşılan Evren \\
\hline 3. Basamak GYB & 47 & 46 \\
2. Basamak GYB & 30 & 29 \\
Koroner YB & 9 & 9 \\
Göğüs YB & 6 & 6 \\
Nöroloji YB & 9 & 8 \\
Genel Toplam & 101 & 98 \\
\hline \multicolumn{2}{l}{ GYB: Genel Yoğun Bakım, YB: Yoğun Bakım }
\end{tabular}

GYB: Genel Yoğun Bakım, YB: Yoğun Bakım

\section{Araştırmanın Veri Toplama Araçları}

Çalışmanın verileri "Hemşire veri toplama formu", ve "REBA (Rapid Entire Body Assessment - Hızlı Tüm Vücut Değerlendirmesi) Çalışan Değerlendirme Formu” ile anket uygulaması, soru cevap ve gözlem yoluyla toplanmıştır.

\section{Hemşire Veri Toplama Formu}

Araştırmacı tarafından oluşturulan formun birinci bölümü hemşirelerin yaş, medeni durum, kronik hastalık varlığı, fiziksel egzersiz yapma durumu, beden kitle indeksi (BKİ), en son mezun olduğu okul, yoğun bakım hemşiresi olarak çalışma süresi olmak üzere 8 adet tanımlayıcı özellikteki soruyu içermektedir. Formun ikinci bölümü hemşirelerin yoğun bakım ünitesindeki görevi, bir aydaki nöbet sayısı ve nöbet süresi, gece gündüz vardiyasında kaç hasta ile çalışıı̆̆ , hastaların yatak içi çevrilmesi, taşınması gibi güç gerektiren durumlarda yardımlı ya da yardımsız çalışma durumu, en çok kullandığı vücut postürü, bakım verirken kullanılan araç gereçlerle ilgili bazı çalışma özellikleriyle ilgili 13 adet soruyu ve boyun, omuz, sırt, dirsek, el/el bileği, bel, kalça/uyluk, diz, ayak/ayak bileği olmak üzere dokuz vücut bölgesinde son on iki ay içindeki ağrı varlığını sorgulayan 9 adet soruyu içerecek şekilde oluşturulmuştur.

\section{REBA (Rapid Entire Body Assessment - Hızlı Tüm Vücut Değerlendirmesi) Çalışan Değerlendirme Formu}

REBA tüm vücut aktiviteleri için hem sabit hem hareketli hızlı postür analizini kolaylaştırmak için Hignett (Nottingham Şehir Hastanesi, Nottingham, Birleşik Krallıklar) ve McAtamney (COPE, İş Sağlığı ve Ergonomi Hizmetleri Ltd., Nottingham, Birleşik Krallıklar) adlı iki ergonomist tarafından tasarlanmıştır. REBA ile bilek, ön kol, dirsek, omuz, boyun ve bel gibi vücudun üst uzuvlarına ek olarak gövde, sırt, bacaklar ve dizler 
değerlendirmeye alınabilmekte, analiz edilmek istenilen duruş veya hareketin neden olduğu toplam risk sayısal olarak ifade edilebilmektedir. REBA'dan elde edilen puanlar ile risk seviyesi değerlendirilebilirken, ayrıca herhangi bir aktivite / girişimin gereklilik derecesi de değerlendirilebilmektedir. REBA skorundan elde edilen puan 1-15 arasında değişmektedir. REBA yöntemi ile statik ve dinamik tüm vücut faaliyetleri esnasında çalışanın duruşu analiz edilerek mesleki kas ve iskelet rahatsızlıklarına sebep olabilecek çalışma duruşlarının saptanması ve gerekli önlemlerin alınabilmesine yol gösteren gözleme dayalı bir duruş analizi metodudur ${ }^{18}$.

REBA yönteminde çalışma ortamında sık tekrarı yapılan, çalışanı zorlayan, uygulanmasında fiziksel güç gerektiren uygulama seçilerek duruş analizi yapılır ${ }^{18}$. REBA yöntemi mühendisliğin temel ergonomik risk değerlendirme araçlarındandır. Literatürde REBA ile ilgili çalışmaların 2000 yılından beri yapıldığı görülmekte olup, hemşirelik alanındaki kullanımı Türkiye için 2018 yılında Kahya ile Aydın Sayılan ve Öztekin'in çalışmalarında görülmektedir ${ }^{19,20}$. REBA'nın Türkçe geçerlilik güvenilirlik çalışması ise henüz yapılmamıştır.

\section{Araştırmanın Etik Boyutu}

Çalışmanın yürütülebilmesi için Eskişehir Osmangazi Üniversitesi Girişimsel Olmayan Klinik Araştırmalar Etik Kurulundan 04.01.2017 tarih ve 80558721/G-12 sayılı onay ve Bursa İli Kamu Hastaneleri Birliği Genel Sekreterliğinden 16.01.2017 tarih ve 1303 sayılı kurum izni alınmıştır. Hemşireler çalışma konusunda bilgilendirildikten sonra yazılı onamları alınmıştır.

\section{Araştırmanın Uygulanması}

Hemşire veri toplama formu; hemşireler tarafından 15 dakikada mesai saatleri içerisinde doldurulurken, REBA Çalışan Değerlendirme Formu; mesai saatleri içerisinde hemşireler hastalarına yatak içi pozisyon verirlerken araştırmacı tarafından gözlem yoluyla doldurulmuştur.

Hemşirelerin vardiyada en çok tekrar ettiği uygulamalardan biri olan hastaya yatak içi pozisyon verme uygulaması seçilerek duruş analizi yapılmıştır. Hemşirelerin mesainin ilerleyen saatlerinde yorgunluklarının artma olasıllı̆̆ nedeniyle mesainin ilk saatlerinde ve ilk hastada duruş analizleri yapılmıştır. Ancak çalışmada hemşirelerin hastalara yatak içi pozisyon verirken vardiyanın farklı saatlerinde ve uygulamanın yapılış sayısı fark etmeksizin hep aynı teknik ve postürle pozisyon verdikleri gözlenmiştir. Bu sebeple hemşirelerin postürleri gözlemlenirken vardiyanın ortak bir saati belirlenmemiştir. Hemşirelere onam alınırken gözlemlenecekleri konusunda bilgi verilmiş ancak gözlem esnasında doğru sonuçlara ulaşabilmek için haber verilmemiş̧ir.

Hemşirelerin çalışma pozisyonu değerlendirme basamakları aşağıda detaylı olarak verilmiştir. 


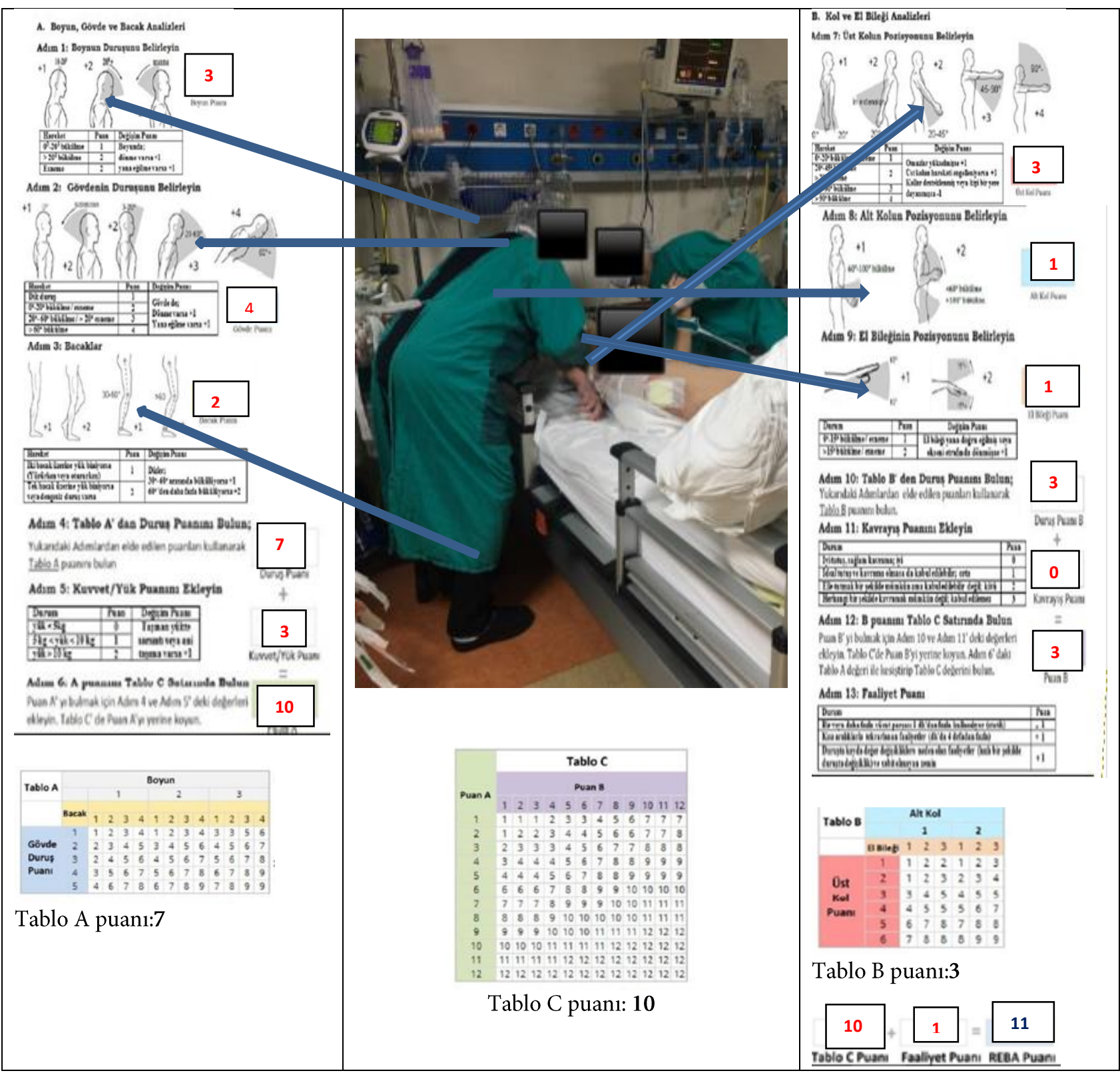

Şekil 1. REBA Formunun Doldurulması Örneği

Tablo 2. REBA Puanlarının Değerlendirilmesi ${ }^{18}$

\begin{tabular}{llll}
\hline REBA puanı & Risk Seviyesi & Önlem & Şekil 2.1 REBA skoru \\
\hline 1 & Kabul edilebilir risk & Gerekli değil & \\
$2-3$ & Düşük risk & Gerekli olabilir & \\
$4-7$ & Orta risk & Gerekli & \\
$8-10$ & Yüksek risk & Kısa zaman içinde gerekli & 11 olup hemen önlem alınması \\
$11-15$ & Çok yüksek risk & Hemen gerekli & gerekmektedir \\
\hline
\end{tabular}

\section{BULGULAR}

Hemşirelerin yaş ortalamasının $32.50 \pm 7.3$ (min. 20; maks. 49) olduğu, \%57.1'inin ( $\mathrm{n}=56)$ evli, \%56.1'inin ( $\mathrm{n}=55)$ lisans düzeyinde eğitim aldığı saptanmıştır. Hemşirelerin \%85.7’sinin $(n=84)$ en az bir kronik hastalığa sahip olduğu, \%63.3'ünün (n=62) fiziksel egzersiz yapmadığı ve beden kitle indeksine göre \%24.5’inin (n=24) fazla kilolu ve \%5.1'inin ( $n=4)$ obez olduğu saptanmıștır.

Hemşirelerin \%46.9'u (n=46) 3. basamak GYB, \%29.6’sı $(n=29)$ 2. basamak GYB, \%9.2'si (n=9) Koroner YB, \%6.1'i (n=6) Göğüs YB ve \%8.2’si (n=8) Nöroloji YB'da görev yaptığı bulunmuştur.

Hemşirelerin çalışma yıl ortalamalarının $10.8 \pm 7.36$ (min.1.4; maks. 29.1) yıl, yoğun bakımda çalışma yıllarının ise $5.4 \pm 4.8$ (min.1.0; maks. 25.0) yıl olduğu, hemşirelerin nöbet tutma sıklıkları ayda ortalama 9.1 \pm 3.8 (min.0.0; 
maks. 15.0) kez olduğu, çalışma vardiya saatlerine göre ise aylı olarak hemşirelerin \%10.2'sinin ( $\mathrm{n}=10)$ sadece 16 saat, \%50'sinin ( $\mathrm{n}=49) 16$ ve 24 saat, \%31.6'si $(\mathrm{n}=31)$ sadece 24 saat ve $\% 8.2^{\prime} \operatorname{sinin}(\mathrm{n}=8)$ sadece gündüz vardiyasında çalışmakta olduğu saptanmıştır. Hemşireler gündüz ve gece vardiyasında ortalama $2.9 \pm 1.2$ (min.2.0; maks. 7.0) hastanın sorumluluğunu aldıklarını belirtmişlerdir.

Hemşirelerin tekrarlı hareketlerde bulundukları pozisyon verme işleminde vücut postürü değerlendirmesi sonucunda REBA'dan aldıkları ortalama puan $8.71 \pm 1.74$ (min. 5.00 - maks. 13.00) olarak bulunmuş, hemşirelerin \%24.5'inin orta derecede, \%63.3'ünün yüksek derecede, \%12.2'sinin çok yüksek derecede risk altında oldukları saptanmıştır. Hemşirelerin REBA risk düzeylerinin yaş, cinsiyet ve çalışılan yoğun bakım ünitesine göre dağılımı Tablo 3 'te gösterilmiştir. Kadınların $\% 67.9$ 'u ve erkeklerin ise $\% 41.2$ 'si yüksek derecede risk altında bulunmuştur. REBA risk düzeyi yüksek olan hemşirelerin 30-34 yaş grubunda olanları \%72.2 ile en yüksek oranda bulunmuş olup, sadece 3. basamak genel yoğun bakım ünitesinde çalşsan hemşirelerin riskinin çok yüksek olduğu saptanmıştır. Yüksek derecede REBA risk düzeyi en fazla (\%72.4) 2. basamak genel yoğun bakımda görüldüğü saptanmıştır.

Tablo 3. Hemşirelerin REBA Risk Düzeylerinin Yaş, Cinsiyet ve Çalışılan Yoğun Bakım Ünitesine Göre Dağılımı

\begin{tabular}{|c|c|c|c|c|}
\hline \multirow[t]{2}{*}{ Değişkenler } & \multicolumn{3}{|c|}{ REBA risk düzeyi } & \multirow{2}{*}{$\begin{array}{c}\text { Toplam } \\
\text { n (\%) }\end{array}$} \\
\hline & $\begin{array}{c}\text { Orta derece } \\
\text { n (\%) }\end{array}$ & $\begin{array}{c}\text { Yüksek } \\
\text { n (\%) }\end{array}$ & $\begin{array}{c}\text { Çok yüksek } \\
\text { n (\%) }\end{array}$ & \\
\hline \multicolumn{5}{|c|}{ Cinsiyet } \\
\hline Kadın & $16(19.8)$ & $55(67.9)$ & $10(12.3)$ & $81(82.7)$ \\
\hline Erkek & $8(47.1)$ & $7(41.2)$ & $2(11.8)$ & $17(17.3)$ \\
\hline \multicolumn{5}{|c|}{ Yaş grupları } \\
\hline$\leq 24$ yaş & $3(15.8)$ & $13(68.4)$ & $3(15.8)$ & $19(19.4)$ \\
\hline $25-29$ yaş & $3(15.8)$ & $12(63.2)$ & $4(21.1)$ & $19(19.4)$ \\
\hline 30-34 yaş & $5(27.8)$ & $13(72.2)$ & $0(0.0)$ & $18(18.4)$ \\
\hline $35-39$ yaş & $7(30.4)$ & $13(56.5)$ & $3(13.0)$ & $23(23.5)$ \\
\hline$\geq 40$ yaş & $6(31.6)$ & $11(57.9)$ & $2(10.5)$ & $19(19.4)$ \\
\hline \multicolumn{5}{|c|}{ Çalışılan yoğun bakım ünitesi } \\
\hline 3.basamak GYB & $4(8.7)$ & $32(69.6)$ & $10(21.7)$ & $46(46.9)$ \\
\hline 2.basamak GYB & $7(24.1)$ & $21(72.4)$ & $1(3.4)$ & $29(29.6)$ \\
\hline Koroner YB & $3(33.3)$ & $5(55.6)$ & $1(11.1)$ & $9(9.2)$ \\
\hline Göğüs YB & $3(50.0)$ & $3(50.0)$ & $0(0.0)$ & $6(6.1)$ \\
\hline Nöroloji YB & $7(87.5)$ & $1(12.5)$ & $0(0.0)$ & $8(8.2)$ \\
\hline Toplam & $24(24.5)$ & $62(63.3)$ & $12(12.2)$ & $98(100.0)$ \\
\hline
\end{tabular}

Hemşirelerin REBA puan ortancalarının bazı sosyo-demografik ve iş - işyeri özelliklerine göre dağılımı Tablo 4'te gösterilmiş̦tir. REBA risk puanları kadınların erkeklerden, BKİ 24.99'un altında olanların BKİ $25^{\prime}$ in üstünde olanlardan, 3. basamak genel yoğun bakım ünitesinde çalışanların nöroloji yoğun bakım ünitesinde çalışanlardan, bekârların evlilerden, yoğun bakım ünitelerinde dinlenme için yeterli koltuk olmadığını belirtenlerin yeterli koltuk olduğunu belirtenlerden daha yüksek bulunmuştur (her biri için; $\mathrm{p}<.05$ ). Ayrıca REBA risk puanının gündüz ve gece vardiyasında dört ve üzeri hastaya bakım veren hemşirelerin iki hastaya bakım veren hemşirelerden daha düşük olduğu saptanmıştır (her biri için; $\mathrm{p}<.05$, Tablo 4). Tabloda belirtilmemekle birlikte hemşirelerin REBA risk puan ortancaları açısından yaş grupları, sigara içme durumu, fiziksel egzersiz yapma durumu, mezun olunan okul, meslekte toplam çalışma yılı ve yeterli dinlenme zamanı arasında anlamlı bir farklılık saptanmamıştır (her biri için; $\mathrm{p}>.05)$. 
Tablo 4. Hemşirelerin REBA Puan Ortancalarının Bazı Sosyo-Demografik ve İş-İsyeri İle İlgili Özelliklere Göre Dağılımı

\begin{tabular}{|c|c|c|c|}
\hline Değişkenler & $\mathbf{n}$ & $\begin{array}{l}\text { Medyan } \\
\text { (min.- maks.) }\end{array}$ & $\begin{array}{c}\text { İstatistiksel analiz } \\
\text { z/KW; p }\end{array}$ \\
\hline \multicolumn{4}{|l|}{ Cinsiyet } \\
\hline Kadın & 81 & $9.00(5.00-13.00)$ & \multirow{2}{*}{$429.500 ; .013$} \\
\hline Erkek & 17 & $8.00(5.00-11.00)$ & \\
\hline \multicolumn{4}{|l|}{$\begin{array}{l}\text { Çalışılan yoğun bakım } \\
\text { ünitesi }\end{array}$} \\
\hline 3.basamak GYB (0) & 46 & $10.00(5.00-11.00)$ & \multirow[t]{5}{*}{$22.259 ; .000$} \\
\hline 2.basamak GYB(1) & 29 & $9.00(5.00-13.00)$ & \\
\hline Koroner YB (2) & 9 & $8.00(7.00-11.00)$ & \\
\hline Göğüs YB (3) & 6 & $7.50(5.00-10.00)$ & \\
\hline Nöroloji YB (4) & 8 & $7.00(5.00-9.00)$ & \\
\hline Gruplar arası karşılaştırma & & & $(0-4)=.000$ \\
\hline \multicolumn{4}{|l|}{ BKi } \\
\hline$<24.99$ & 69 & $9.00(5.00-13.00)$ & \multirow[b]{2}{*}{$694.500 ; .015$} \\
\hline$>25.00$ & 29 & $8.00(5.00-11.00)$ & \\
\hline \multicolumn{4}{|l|}{ Medeni durum } \\
\hline Evli & 56 & $8.50(5.00-13.00)$ & \multirow{2}{*}{$1619.500 ; .001$} \\
\hline Bekar & 42 & $10.00(5.00-11.00)$ & \\
\hline \multicolumn{4}{|l|}{ Çalışma vardiyası } \\
\hline Sadece 16 saat & 10 & $9.00(7.00-11.00)$ & \multirow{4}{*}{$2.101 ; .552$} \\
\hline 16 ve 24 saat & 49 & $9.00(5.00-11.00)$ & \\
\hline Sadece 24 saat & 31 & $9.00(5.00-13.00)$ & \\
\hline Sadece 8 saat & 8 & $8.00(7.00-10.00)$ & \\
\hline \multicolumn{4}{|c|}{ Dinlenme için yeterli koltuk varlığı } \\
\hline Var & 34 & $8.00(5.00-11.00)$ & \multirow{2}{*}{$773.50 ; .017$} \\
\hline Yok & 64 & $9.00(5.00-13.00)$ & \\
\hline \multicolumn{4}{|c|}{ Gündüz vardiyasında çalışılan ortalama hasta sayısı } \\
\hline 2 & 46 & $10.00(5.00-11.00)$ & \multirow{4}{*}{$19.642 ; .000$} \\
\hline 3 & 29 & $9.00(5.00-13.00)$ & \\
\hline 4 & 13 & $7.00(5.00-11.00)$ & \\
\hline 5 ve üzeri & 10 & $7.00(5.00-10.00)$ & \\
\hline Gruplar arası karşılaştırma & & $(4-2)=.002$ & \\
\hline \multicolumn{4}{|c|}{ Gece vardiyasında çalışılan ortalama hasta sayısı } \\
\hline 2 & 46 & $10.00(5.00-11.00)$ & \multirow{4}{*}{$19.349 ; .000$} \\
\hline 3 & 30 & $9.00(5.00-13.00)$ & \\
\hline 4 & 11 & $7.00(5.00-11.00)$ & \\
\hline 5 ve üzeri & 11 & $7.00(5.00-10.00)$ & \\
\hline Gruplar arası karşılaştırma & \multirow{2}{*}{\multicolumn{3}{|c|}{$(5-2)=.003 ;(4-2)=.007$}} \\
\hline Toplam & & & \\
\hline
\end{tabular}

Hemşirelerin REBA puan ortancalarının yoğun bakım ünitelerindeki ergonomik risk faktörleri üzerine dağılımı Tablo 5'te gösterilmiştir. Yoğun bakım ünitelerinde bakım esnasında mekanik zorlanmaya neden olabilecek uygulamalardan alt bezi değişim işlemini tek kişi yapan hemşirelerin REBA risk puanları yardımla yapan hemşirelerden daha yüksek bulunmuştur $(\mathrm{p}<.05)$. Yoğun bakım ünitelerinde bakım esnasında mekanik zorlanmaya neden olabilecek uygulamalardan hastaya pozisyon verme, taşıma, banyo yaptırma, aktif-pasif egzersiz uygulaması, basınç yaralanması bakımı, çarşaf değişimi, mobilizasyon ve genel vücut bakımı ile REBA risk puanları arasında istatistiksel olarak anlamlı bir ilişki saptanmamıştır (her biri için; $p>.05$ ). Yine, yoğun bakım ünitelerinde en çok çalışılan postür, hastaya bakım verirken kullanılan araç gereçler, kullanılan malzemelerin yüksekliklerinin kendi boyuna göre ayarlanması, hemşirelerin sahip oldukları kronik hastalıklar ve hemşirelerin beden mekaniklerinde (ayakta pozisyonda, adım şekli, eğilme şekli, kavrama şekli, taşıma şekli, oturma şekli, hastayı çekme şekli) en çok tercih ettikleri pozisyonlar ile REBA risk puanları arasında istatistiksel olarak anlamlı bir ilişki saptanmamıştır (her biri için; $\mathrm{p}>.05$; Tablo 5).

Tablo 5. Hemşirelerin REBA Puan Ortancalarının Yoğun Bakım Ünitelerindeki Ergonomik Risk Faktörleri Üzerine Dağılımı 


\begin{tabular}{|c|c|c|c|}
\hline Değişkenler & $\mathbf{n}$ & $\begin{array}{c}\text { Medyan } \\
\text { (min.- maks.) }\end{array}$ & $\begin{array}{c}\text { İstatistiksel analiz } \\
\text { z/KW;p }\end{array}$ \\
\hline \multicolumn{4}{|l|}{ Pozisyon verme } \\
\hline Tek kişi & 6 & $10.00(8.00-11.00)$ & \multirow{2}{*}{$161.00 ; .082$} \\
\hline Yardımla & 92 & $9.00(5.00-13.00)$ & \\
\hline \multicolumn{4}{|l|}{ Taşıma / transport } \\
\hline Tek kişi & 4 & $9.50(9.00-11.00)$ & \multirow{2}{*}{$121.50 ; .223$} \\
\hline Yardımla & 94 & $9.00(5.00-13.00)$ & \\
\hline \multicolumn{4}{|l|}{ Banyo } \\
\hline Tek kişi & 3 & $10.00(9.00-11.00)$ & \multirow{2}{*}{$76.00 ; .162$} \\
\hline Yardımla & 95 & $9.00(5.00-13.00)$ & \\
\hline \multicolumn{4}{|l|}{ Aktif- pasif egzersiz } \\
\hline Tek kişi & 37 & $9.00(5.00-13.00)$ & \multirow{2}{*}{$1090.00 ; .774$} \\
\hline Yardımla & 61 & $9.00(5.00-11.00)$ & \\
\hline \multicolumn{4}{|l|}{ Basınç yaralanmasında bakım } \\
\hline Tek kişi & 26 & $9.00(5.00-13.00)$ & \multirow{2}{*}{$941.50 ; .964$} \\
\hline Yardımla & 72 & $9.00(5.00-11.00)$ & \\
\hline \multicolumn{4}{|l|}{ Çarşaf değişimi } \\
\hline Tek kişi & 7 & $10.00(8.00-11.00)$ & \multirow{2}{*}{$221.50 ; .172$} \\
\hline Yardımla & 91 & $9.00(5.00-13.00)$ & \\
\hline \multicolumn{4}{|l|}{ Alt bez değişimi } \\
\hline Tek kişi & 6 & $10.00(9.00-11.00)$ & \multirow{2}{*}{$143.00 ; .044$} \\
\hline Yardımla & 92 & $9.00(5.00-13.00)$ & \\
\hline \multicolumn{4}{|l|}{ Mobilizasyon } \\
\hline Tek kişi & 5 & $9.00(7.00-11.00)$ & \multirow{2}{*}{$216.50 ; .792$} \\
\hline Yardımla & 93 & $9.00(5.00-13.00)$ & \\
\hline \multicolumn{4}{|l|}{ Genel vücut bakımı } \\
\hline Tek kişi & 7 & $9.00(5.00-11.00)$ & \multirow{2}{*}{$332.50 ; .844$} \\
\hline Yardımla & 91 & $9.00(5.00-13.00)$ & \\
\hline \multicolumn{3}{|l|}{ Kronik hastalık varlığı } & \multirow{4}{*}{$617.50 ; .760$} \\
\hline Var & 14 & $9.00(5.00-11.00)$ & \\
\hline Yok & 84 & $9.00(5.00-13.00)$ & \\
\hline Toplam & 98 & $9.00(5.00-13.00)$ & \\
\hline
\end{tabular}

Tablo 5. Hemşirelerin REBA puan ortancalarının yoğun bakım ünitelerindeki ergonomik risk faktörleri üzerine dağılımı (Devamı)

\begin{tabular}{|c|c|c|c|}
\hline Değişkenler & $\mathbf{n}$ & $\begin{array}{l}\text { Medyan } \\
\text { (min.- maks.) }\end{array}$ & $\begin{array}{c}\text { İstatistiksel analiz } \\
\text { z/KW;p }\end{array}$ \\
\hline \multicolumn{4}{|l|}{ En çok çalışılan postür } \\
\hline $\begin{array}{l}\text { Oturarak ve dik ayakta (iki } \\
\text { ayaküstünde dengeli) }\end{array}$ & 60 & $9.00(5.00-13.00)$ & \multirow{2}{*}{$1302.50 ; .227$} \\
\hline $\begin{array}{l}\text { Dik ayakta (tek ayaküstüne } \\
\text { ağırlık vererek) ve eğilerek }\end{array}$ & 38 & $9.00(5.00-11.00)$ & \\
\hline \multicolumn{4}{|l|}{ Kullanılan araç gereçler } \\
\hline Transfer sandalyesi & 72 & $9.00(5.00-13.00)$ & \multirow{2}{*}{$930.00 ; .961$} \\
\hline Diğer & 26 & $9.00(7.00-11.00)$ & \\
\hline \multicolumn{4}{|c|}{ Malzeme yüksekliklerini kendi boyuna göre ayarlama } \\
\hline Evet & 79 & $9.00(5.00-13.00)$ & \multirow{2}{*}{$770.50 ; .855$} \\
\hline Hayır & 19 & $9.00(5.00-11.00)$ & \\
\hline \multicolumn{4}{|c|}{ Hemşirelerin beden mekaniklerinde en çok tercih ettikleri pozisyonlar } \\
\hline \multicolumn{4}{|l|}{ Ayakta pozisyonda } \\
\hline Dik duruş & 62 & $8.62(5.00-11.00)$ & \multirow{2}{*}{$1.151 ; .790$} \\
\hline Kambur duruş & 36 & $8.86(5.00-13.00)$ & \\
\hline \multicolumn{4}{|l|}{ Adım şekli } \\
\hline Dik adım & 75 & $8.61(5.00-11.00)$ & \multirow{2}{*}{$974.500 ; .338$} \\
\hline Kambur adım & 23 & $9.04(5.00-13.00)$ & \\
\hline
\end{tabular}




\begin{tabular}{|c|c|c|c|}
\hline Eğilme şekli & & & \\
\hline Diz kırarak eğilme & 62 & $8.51(5.00-11.00)$ & \multirow{2}{*}{$1.308 ; .148$} \\
\hline Diz kırmadan eğilme & 36 & $9.05(5.00-13.00)$ & \\
\hline \multicolumn{4}{|l|}{ Kavrama şekli } \\
\hline Tam önde kavrama & 27 & $8.66(5.00-13.00)$ & \multirow{2}{*}{$999.500 ; .740$} \\
\hline Önde-yanda kavrama & 71 & $8.73(5.00-11.00)$ & \\
\hline \multicolumn{4}{|l|}{ Taşıma şekli } \\
\hline Bel dik taşıma & 19 & $9.05(5.00-13.00)$ & \multirow{2}{*}{$645.00 ; .334$} \\
\hline Bel eğik taşıma & 79 & $8.63(5.00-11.00)$ & \\
\hline \multicolumn{4}{|l|}{ Oturma şekli } \\
\hline Dik oturma & 60 & $8.85(5.00-13.00)$ & \multirow{2}{*}{$998.500 ; .293$} \\
\hline Eğik oturma & 38 & $8.50(5.00-11.00)$ & \\
\hline \multicolumn{4}{|l|}{ Hastayı çekme şekli } \\
\hline Hastaya yaklaşarak çekme & 49 & $8.91(5.00-13.00)$ & \multirow{2}{*}{$1.030 ; .218$} \\
\hline Hastadan uzaklaşarak çekme & 49 & $8.51(5.00-11.00)$ & \\
\hline Toplam & 98 & $9.00(5.00-13.00)$ & \\
\hline
\end{tabular}

Hemşirelerin REBA puan ortancalarının son 12 ay içerisindeki kas iskelet sistemi ağrılarına ve ağrı lokalizasyonlarına göre dağılımı gösterilmiştir. Hemşirelerden kas iskelet sistemlerinde ağrı şikâyeti olanların, kas iskelet sistemindeki ağrı lokalizasyonlarından boyun bölgesinde, omuz bölgesinde, sırt bölgesinde ve ayak-ayak bileğinde ağrısı olanların REBA puanları daha yüksek bulunmuştur (her biri için; p <.05, Tablo 6).

Tablo 6. Hemşirelerin REBA Puan Ortancalarının Son 12 Ay İçerisinde Hemşirelerin Kas İskelet Sistemi Ağrılarına ve Ağrı Lokalizasyonlarına Göre Dağılımı

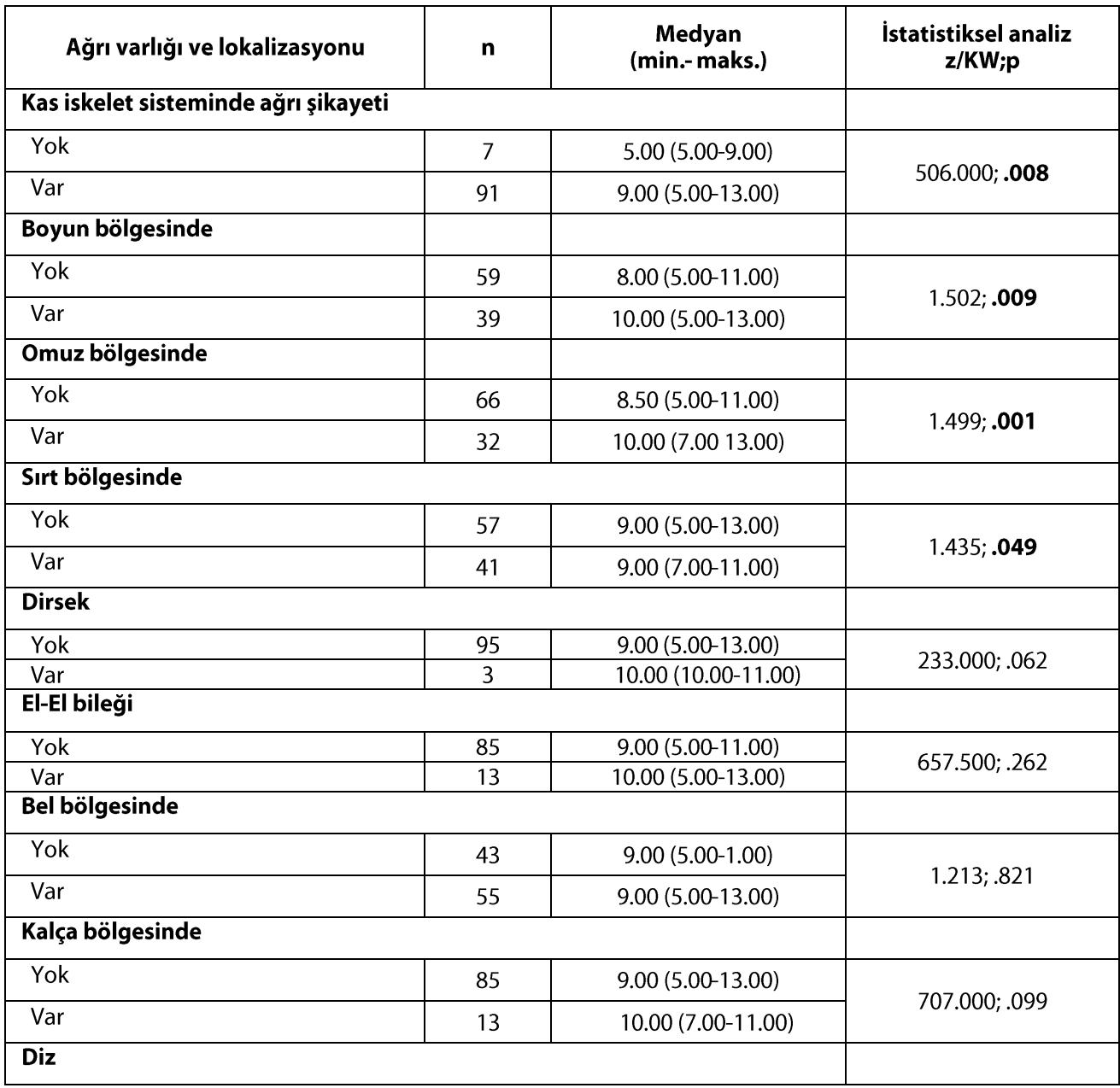




\begin{tabular}{|l|l|l|l|}
\hline Yok & 69 & $9.00(5.00-11.00)$ & \multirow{2}{*}{$1.117 ; .355$} \\
\cline { 1 - 2 } Var & 29 & $9.00(5.00-13.00)$ & \\
\cline { 1 - 3 } Ayak-Ayak bileği & 67 & $9.00(5.00-11.00)$ & \multirow{2}{*}{$1.292 ; .048$} \\
\hline Yok & 31 & $10.00(5.00-13.00)$ & \\
\hline Var & 98 & $9.00(5.00-13.00)$ & \\
\cline { 1 - 2 } Toplam &
\end{tabular}

\section{TARTIŞMA}

Çalışmamızda hemşirelerin çalı̧̧ma duruşlarındaki risk düzeyleri incelendiğinde dörtte birinin orta derecede, yarıdan fazlasının yüksek derecede, çok az bir bölümünün ise çok yüksek derecede ergonomik açıdan risk altında olduğu bulunmuştur. Bu durumda yatakta pozisyon verme işleminin yüksek ve çok yüksek risk derecesinde olduğu, kısa zaman içinde ve hemen ergonomik önlem alınması gerekli olduğu görülmektedir. Abdollahzade ve arkadaşlarının ameliyathane hemşireleri üzerinde yaptıkları çalışmada hemşirelerin üçte birinin orta derecede, yarısının yüksek derece ve çok az bir bölümünün da çok yüksek derecede risk altında olduğu bulunmuştur ${ }^{21}$. Çalışmamızda hemşirelerin tekrarlı hareketlerde bulundukları hastaya "pozisyon verme" işleminde vücut postürü değerlendirmesi sonucunda ergonomik açıdan yüksek risk grubunda yer aldıkları bulunmuştur (Tablo 2). Literatürde bu sonuçtan daha düşük bildirilen REBA puanları olduğu gibi daha yüksek olduğunu bildiren çalışmalarda bulunmaktadır ${ }^{19,20,22,23}$. Aydın Sayılan ve Öztekin'in ameliyathane hemşireleri üzerinde yaptıkları bir çalışmada hemşirelerin REBA puanlarının ortalama 6,9 olduğu ve orta derece risk grubunda yer aldıkları aktarılmaktadır ${ }^{20}$. Ratzon ve arkadaşları kas iskelet ağrısı olan hemşireler üzerinde uyguladıkları egzersiz programılla REBA puan ortalamasını 6.35 'ten 2.07’ye düşürmeyi başarmışlardır ${ }^{22}$. Kahya ve arkadaşlarının yoğun bakım hemşireleri üzerinde yaptıkları bir çalışmada en yüksek REBA skoru olan kırışmış çarşaf düzenleme ve gerdirme işleminde kullanılması önerilen hasta taşıma lifti ile REBA skoru 9'dan 2'ye; hastayı yatağın başına çekme işleminde kaydırıcı çarşaf kullanımıyla REBA skoru 9'dan 3'e düşeceği aktarılmıştır' ${ }^{19}$. Abdalla ve arkadaşlarının çalışmasında yoğun bakım hemşirelerinin hastalara bakım ve tedavi uygularken farklı duruş analizlerindeki saptadıkları REBA puanları 7 ile 11 arasında değisstiği aktarılmaktadır ${ }^{23}$. REBA puanları arasındaki farklılı̆ın nedeni; hemşirelerin ilaç hazırlama, ilaç uygulama, yatak yapma, hastanın giyinmesine yardım etme, yatak içi banyo yaptırma, hastanın takibi, kan alma, infüzyon, tüple besleme gibi çeşitli hemşirelik girişimlerindeki duruşun farklı olmasından kaynaklanıyor olabilir. Yine de REBA skorlarının yüksek olması yoğun bakım hemşirelerinin yaptıkları işlemlerde kullandıkları vücut postürlerinin kas iskelet sistemi hastalıkları / rahatsızlıkları için risk oluşturduğunu ve önlem alınması gerektiğini ortaya koymaktadır.

Kadınların kas iskelet sistemi sorunları üzerinde erkeklere göre genetik, hormonal, psikolojik farklılıklarının olmasının ve ev ortamında kadına yüklenen toplumsal rollerin etkili olduğu belirtilmektedir ${ }^{24-26}$. En önemlisi de erkeklerle kadınlar arasında fiziksel güç (kas gücü) açısından fizyolojik farklılıklar vardır. Bu nedenle yük kaldırma, taşıma gibi ağır fiziksel aktivite gerektiren işler sırasında kadınlar, uygun olmayan çalışma duruşları ve kas iskelet sistemi sorunları açısından erkeklere göre daha riskli durumdadırlar ${ }^{27}$. Sanayi kollarında yapılan kas-iskelet sistemi rahatsızlıklarının değerlendirildiği çalışmalarda da kadınların erkeklerden daha yüksek KİSR prevelansına sahip olduğu aktarılmaktadır ${ }^{28-31}$. Çalışmamızda kadınların REBA risk puanı erkeklerden yüksek bulunmuștur (Tablo 4). Hemşirelerin kas iskelet ağrılarının değerlendirildiği bir çalışmada kadın olmanın kas iskelet ağrısını arttıran önemli risk faktörlerinden olduğu aktarılmaktadır ${ }^{32}$. Literatürde BKÍnin kas iskelet sistemi kaynaklı ağrııı arttıran en önemli risk faktörlerinden biri olduğunu aktaran çalışmalar mevcuttur ${ }^{32-34}$. Çalışmamızda BKİ 24.99'un altında olanların REBA risk puanı daha yüksek bulunmuştur (p <.05; Tablo 4).

Çalışmamızda bekar olanların REBA risk puanı evli olanlardan daha yüksek bulunmuştur (Tablo 4). Bekar hemşirelerin daha çok yoğun bakım ünitelerinde çalıştırılması, nöbet sayılarının daha fazla olması, tecrübesiz olması gibi nedenlerle REBA risk puanlarının fazla olabileceği düşünülmektedir. Literatürde bu iki değisşkeni doğrudan kıyaslayan bir çalı̧maya rastlanmamıştır. Ancak evli olmanın kas iskelet sistemi ağrıları için risk olduğunu aktaran çalışmalar bulunmaktadır ${ }^{35,36}$.

Yoğun bakım ünitelerinde hemşirelerin dinlenmesi için yeterli koltuk olmadığını belirtenlerin REBA risk puanı yeterli koltuk olduğunu belirtenlerden daha yüksektir (Tablo 4). Yoğun bakım ünitelerinde yeterli koltuk ve sandalye olmayışı sebebiyle hemşireler hastaya uyguladıkları bakım ve tedavi süreçleri dışında da uzun süre ayakta 
kalmakta, bunun yanı sıra, dinlenme ve hasta odalarındaki sandalyeler yükseklikleri ayarlanabilen, sırt destekleri olan özellikte de değildir. Sandalyenin çalışana göre ayarlanabilir olmaması, hemşirelerin yazı yazarken ve bilgisayar başındayken gereksiz eğilme ve bükülme hareketleri yapmasına neden olmaktadır. Uygun olmayan çalışma duruşları ve ekipmanları sebebiyle kas-iskelet sistemi üzerindeki riskin arttığı düşünülmektedir.

Çalışmamızda gündüz ve gece vardiyasında dört ve üzeri hastaya bakım veren hemşirelerin REBA risk puanı iki hastaya bakım veren hemşirelerden daha düşüktür (her biri için; $\mathrm{p}<.05$; Tablo 4). Bu durum iki hastaya bakım verilen yoğun bakım ünitelerindeki (ikinci ve üçüncü basamak genel yoğun bakım üniteleri) hastaların pozisyon verilme esnasında hemşirelere daha bağımlı olmalarından kaynaklandığı düşünülmektedir.

Çalışma alanının vücut mekaniğine uygun olmayan tasarımı ve doğru olmayan vücut duruş ve hareketlerinin tekrarlı olarak uygulanması sonucunda kas iskelet sistemi rahatsızlıkları görülmektedir ${ }^{28,37}$. Serranheira ve arkadaşları hemşirelerin yaptıkları işlerin günlük tekrarlarını araştırmış ve hemşirelerin büyük bir çoğunluğunun 5, dörtte birinin ise 6 kereden fazla yatak içi hasta temizliği ve bakımı yaptığını, yine büyük bir çoğunluğunun günde 5 kez ve daha az mekanik yardımcı olmadan neredeyse tamamının ise mekanik bir yardımcıyla hastayı kaldırdığını, üçte birinin 6 kereden fazla invaziv girişimde bulunduğunu bildirmişlerdir ${ }^{38}$. Görüldüğü gibi hemşireler hasta bakım uygulamalarındaki görevlerini yoğun bakım ünitelerinde tekrarlı olarak uygulamaktadırlar. Çalışmamızda hemşirelerin beden mekaniklerini kullanımlarıyla ilgili bazı pozisyonlardan hangilerini daha çok kullandıkları incelendiğinde; çoğunun doğru beden mekaniklerini kullandığı saptanmıştır (Tablo 5).

Benzer olarak Güler’in hemşirelerin duruşlarını değerlendirdiği çalışmasında hemşirelerin büyük çoğunluğunun dik duruş, dik adım, tam önde kavrama, diz kırarak eğilme, bel dik taşıma ve hastaya yaklaşarak hastayı çekme gibi doğru beden mekanikleri kullanırken, yarısından biraz fazlasının ise yanlış bir beden mekaniği olan eğik oturuş pozisyonlarını kullandığı aktarılmıştı7. Şirzai ve arkadaşları çalışma esnasında uygun postürde çalışmamanın boyun, omuz, sırt ve el bileği ağrıları için, uzun süre aynı pozisyonda çalışmanın da omuz ağrısı için risk faktörü olduğunu aktarmaktadır ${ }^{34}$. TÜİK tarafından çalışma ortamında fiziksel sağlığı etkileyen faktörler incelendiğinde iş yerinde ağır yük taşıma, zor duruş şekli veya harekete maruz kalma oranının fiziksel sağlı̆̆ı etkilediği bildirilmiştir ${ }^{39}$. Hemşirelerin kas iskelet rahatsızlıklarından korunmak için uygulamalar esnasında beden mekaniklerini korumaya özen göstermeleri gerekmektedir.

Hemşirelerin mekanik zorlanmaya neden olabilecek uygulamaları yardım almadan yapması ile kas iskelet sistemi hastalıklarının sıklığı arasında ilişki bulunmaktadır ${ }^{40}$. Çalışmamızda yoğun bakım ünitelerinde bakım esnasında mekanik zorlanmaya neden olabilecek uygulamalardan alt bezi değişim işlemini tek kişi yapan hemşirelerin REBA risk puanları yardımla yapan hemşirelerden daha yüksektir (Tablo 5). Mekanik zorlanmaya neden olabilecek uygulamalardan çoğu personel yardımıyla uygulanmaktadır. Ancak, tek başına yapılan uygulamalar sırasında uzanma hareketinin hem omurgada hem omuzlarda zorlanmaya yol açacak duruş pozisyonlarına sebep olduğu düşünülebilir. Yoğun bakımlarda hastaya pozisyon verilmesi ve hasta transferleri sırasında NIOSH'un önerdiği 15.9 kg'lık limitin aşıldığı ve işle ilgili kas iskelet bozukluklarının mekanik zorlanmaya sebep olabilecek ağır nesneleri kaldırma gibi faaliyetlerle yakından ilişkili olduğu düşünülmektedir ${ }^{41}$.

\section{SONUÇ ve ÖNERILER}

Yoğun bakımda çalışan hemşirelerin çoğunda hastaya pozisyon verme faaliyetleri nedeniyle kas iskelet problemi bulunmaktadır. Hastaya pozisyon verme faaliyetinde yoğun bakımda çalışan hemşirelerin ergonomik riski 3. Basamakta çok yüksek, 2. Basamakta ise yüksek olup acil önlem alınması gerekmektedir. Hastaya pozisyon verme faaliyeti REBA puanları yüksek olan hemşirelerin boyun bölgesinde, omuz bölgesinde, sirt bölgesinde ve ayak-ayak bileğinde ağrısı vardır. Yoğun bakımlarda hastaya pozisyon verme işleminde hemşirelerin yükünü azaltan yatakların / yardımcı cihazların kullanılması yararlı olacaktır.

\section{KAYNAKLAR}

1. WHO. WHO global plan of action on workers' health (2008-2017): Baseline for implementation. Geneva, Switzerland: World Health Organization; 2013.

2. Yılmaz E, Özkan S. Hastanede çalışan hemșirelerde bel ağrısı prevelensının saptanması. Türk Fiz Tıp Rehab Derg. 2008;54:8-12.

3. Saygün M. Sağlık çalışanlarında iş sağllğ̆ ve güvenliği sorunları. TAF Preventive Medicine Bulletin. 2012;11(4):373-382.

4. Ceylan H, Başhelvacı VS. Risk değerlendirme tablosu yöntemi ile risk analizi: bir uygulama. International Journal of Engineering Research and Development. 2011;3(2):25-33.

5. Güngörmüş Z. Çalışan sağlığı ve çalışma güvenliği. In: Erci B, editor. Halk Sağlığı Hemşireliği. Amasya: Göktuğ Yayıncılık; 2012; 284312 
6. Berk M, Önal B, Güven R. Meslek Hastalıkları Rehberi. 2011. Ankara: alışma ve Sosyal Güvenlik Bakanlığı, İş Sağlığı ve Güvenliği Genel Müdürlüğü [11-32].

7. Güler T, Yıldız T, Önler E, Yıldız B, G. G. Hastane ergonomik koşullarının hemşirelerin mesleki kas iskelet sistemi rahatsızlıkları üzerine etkisi. IAAOJ, Scientific Science,. 2015;3(1):1-7.

8. Babayiğit MA, Kurt M. Hastane ergonomisi. İstanbul Tip Dergisi. 2013;14:153-159.

9. Gupta S. Ergonomic applications to dental practice. Indian Journal of Dental Research. 2011;22(6):816-822.

10. Önal B. Kas İskelet Hastalıklarının Ülkemizdeki Durumu ve İlgili Yasal Düzenlemeler. İş Sağllğı ve Güvenliği Dergisi. 2007;34:15-19.

11. Fujishiro K, Weaver JL, Heaney CA, Hamrick CA, Marras WS. The effect of ergonomic interventions in healthcare facilities on musculoskeletal disorders. American Journal of Industrial Medicine. 2005;48:338-347.

12. Nelson A, Matz M, Chen F, Siddharthan K, Lloyd J, Fragala G. Development and evaluation of a multifaceted ergonomics program to prevent injuries associated with patient handling tasks. International Journal of Nursing Studies. 2006;43(6):717-733.

13. Alp E, Bozkurt M, Başçiftçi İ. Hastane malzemelerinin sağlık çalışanlarının postürüne etkileri. Sakarya Üniversitesi Fen Bilimleri Enstitüsü Dergisi. 2012:221-226.

14. Pompei LA, Lipscomb HJ, Schoenfisch AL. Musculoskeletal injuries resulting from patient handling tasks among hospital workers. American Journal of Industrial Medicine. 2009;52(7):571-578.

15. Pinar R. Work-related musculoskeletal disorders in Turkish hospital nurses. Turkiye Klinikleri Journal of Medical Sciences. 2010;30(6):1869-1875.

16. Freimann T, Merisalu E, Pääsuke M. Effects of a home-exercise therapy programme on cervical and lumbar rangeof motion among nurses with neck andlower back pain: a quasi-experimental study. BMC Sports Science Medicine and Rehabilitation. 2015;7(31):1-7.

17. Esin NM, Sezgin D. Intensive Care Unit Workforce: Occpational HEalth and Safety, Chapter 10. Intensive Care: Intech; 2017;199-216.

18. Hignett S, McAtamney L. Technical note: Rapid Entire Body Assessment (REBA). Applied Ergonomics. 2000;31:201-205.

19. Kahya E, Gülbandılar S, Gürleyen E. Nöroloji Yoğun Bakım Ünitesinde Çalışan Hemşirelerin Maruz Kaldığı Fiziksel Zorlanmaların Analizi. Ergonomics. 2018;1(1):39-48.

20. Sayılan Aydın A, Öztekin S. Ameliyathane Hemşirelerinin Vücut Postürleri ve İlişkili Faktörler. Gümüşhane Üniversitesi Sağlık Bilimleri Dergisi. 2018;7(1):23-27.

21. Abdollahzade F, Mohammadi F, Dianat I, Asghari E, Asghari Jafarabadi M, Sokhanvar Z. Working posture and its predictors in hospital operating room nurses. Health Promotion Perspectives. 2016;6(1):17-22.

22. Ratzon NZ, Bar-Niv NA, Froom P. The effect of a structured personalized ergonomic intervention program for hospital nurses with reported musculoskeletal pain: An assigned randomized control trial. Work 2016;54:367-377.

23. Abdalla DR, Freitas FS, Matheus JPC, Walsh IAP, Bertoncello D. Postural biomechanical risks for nursing workers. Scielo Analyties. 2014;27(3):421-427.

24. Lederer V, Rivard M, Mechakra-Tahiri SD. Gender Differences in Personal and Work-Related Determinants of Return-to-Work Following Long-Term Disability: A 5-Year Cohort Study. Journal of Occupational Rehabilitation. 2012; 22(4):522-531.

25. Frediksson K, Alfredsson L, Ahlberg G, Josephson M, Kilbom A, Hjelm EW, et al. Work environment and neck and shoulder pain: the influence of exposure time. Results from a population based case-control study. Occupational and Environmental Medicine. 2002;59(3):182-187.

26. Das B. Gender differences in prevalence of musculoskeletal disorders among the rice farmers of West Bengal, India. Work. 2015;50(2):229-240.

27. Bilir N, Yıldız AN. Çalışma hayatında kadın. İş sağlığı ve güvenliği. Genişletilmiş İkinci Baskı ed. Ankara: Hacettepe Üniversitesi Yayınları; 2014. p. 147-57.

28. Lu JM, Twu LJ, Wang MJJ. Risk assessments of work-related musculoskeletal disorders among the TFT-LCD manufacturing operators. International Journal of Industrial Ergonomics. 2016;52:40-51.

29. Çalık BB, Atalay OT, Başkan E, Gökçe B. Bilgisayar kullanan masa başı çalışanlarında kas iskelet sistemi rahatsızlıkları, işin engellenmesi ve risk faktörlerinin incelenmesi. MÜSBED. 2013;3(4):208-14.

30. Karlqvist L, Tornqvist EW, Hagberg M, Hagman M, Toomingas A. Self-reported working conditions of VDU operators and associations with musculoskeletal symptoms: a cross-sectional study focussing on gender differences. International Journal of Industrial Ergonomics. 2002;30:277-94.

31. Widanarko B, Legg S, Stevenson M, Devereux J, Eng A, Mannetje A, et al. Prevalence of musculoskeletal symptoms in relation to gender, age, and occupational/industrial group. International Journal of Industrial Ergonomics. 2011;41(5):561-72.

32. Gül A, Üstündağ H, Kahraman B, Purisa S. Hemşirelerde Kas İskelet Ağrılarının Değerlendirilmesi. HSP. 2014:1-10.

33. Cımbız A, Uzgören N, Aras Ö, Öztürk S, Elem E, Aksoy CC. Kas iskelet sisteminde ağrıya ait risk faktörlerinin lojistik regresyon analizi ile belirlenmesi: pilot çalışma. Fizyoterapi Rehabilitasyon Dergisi. 2007;18(1):20-7.

34. Şrzai H, Doğu B, Erdem P, Yılmaz F, Kuran B. Hastane çalışanlarında işe bağlı kas iskelet sistemi hastalıkları: üst ekstremite problemleri. Şişli Etfal Hastanesi Tıp Bülteni. 2015;49(2):135-41.

35. Koçoğlu D, Özdemir L. Yetişkin nüfusta ağrı ve ağrı inançlarının sosyo-demografik ekonomik özelliklerle ilişkisi. Ağrı. 2011;23(2):6470.

36. Abedini R, Choobineh A, Hasanzadeh J. Musculoskeletal load assessment in hospital nurses with patient transfer activity. International Journal of Occupational Hygiene. 2013;5(2):39-45.

37. Esen $\mathrm{H}$, Fığlalı $\mathrm{N}$. Çalışma duruşu analiz yöntemleri ve çalışma duruşunun kas-iskelet sistemi rahatsızlıklarına etkileri. Sakarya Üniversitesi Fen Bilimleri Enstitüsü Dergisi. 2013;17(1):41-51

38. Serranheira F, Sousa-Uva M, Sousa-Uva A. Hospital nurses tasks and work-related musculoskeletal disorders symptoms: a detailed analysis. Work. 2015;51:401-9.

39. TUİK. İş kazaları ve işe bağlı sağlık problemleri araştırma sonuçları. 2013.

40. İlçe A. Study on work-related musculoskeletal dısorders in intensıve care unit nurses. Anatolian Journal of Clinical Investigation. 2014;8(2):68-76

41. NIOSH. Safe patient handling and mobility (SPHM): The National Institute for Occupational Safety and Health (NIOSH); 2018 [cited 201812 Ocak]. Available from: https://www.cdc.gov/niosh/topics/safepatient/. 